\title{
Drug Development for PCGF2 Protein, Involved in Formation of Human Breast Cancer by Polyphenols and Their Derivatives Extracted from Cowania maxicana
}

\author{
Jawaria Khan*, Ardas Masood, Asma Noor, Muhammad Imran Qadir \\ Institute of Molecular Biology and Biotechnology, Bahaudin Zakariya University, Multan, Pakistan \\ E-mail address: \\ jiakhan77777@gmail.com (J. Khan) \\ *Corresponding author \\ To cite this article: \\ Jawaria Khan, Ardas Masood, Asma Noor, Muhammad Imran Qadir. Drug Development for PCGF2 Protein, Involved in Formation of \\ Human Breast Cancer by Polyphenols and Their Derivatives Extracted from Cowania maxicana. International Journal of Pharmacy and \\ Chemistry. Vol. 3, No. 6, 2017, pp. 77-81. doi: 10.11648/j.ijpc.20170306.12
}

Received: May 28, 2017; Accepted: October 8, 2017; Published: November 15, 2017

\begin{abstract}
In women, the most commonly found cancer is breast cancer. PCGF2 (polycomb group RING finger protein 2) was found to be one of the reasons that cause breast carcinoma in women. Ring finger protein causes formation of multiprotein complexes and mediates interactions between different proteins. The polyphenols, extracted from Cowania maxicana and their derivatives were found to have anti proliferative activities. They showed greater efficiency and specificity towards the target protein PCGF2 (polycomb group RING finger protein 2).
\end{abstract}

Keywords: Breast Cancer, PCGF2, Polyphenols, Cowania maxicana, Pedunculagin

\section{Introduction}

A tumor that is present in the area of breast in the humans is called adenocarcinoma. Breast cancer is one of the most common cancers occurring in human and cover $18 \%$ of all cancers and nearly 1 in 3 cancers diagnosed among women in the United States (DeSantis et al., 2011).

There are many methods to treat cancer e.g. surgery, radiation therapy and chemotherapy. The clinical way of a patient having breast carcinoma stays tricky to predict, as tumors of apparently homogenous morphological characteristics still differ in response to therapy and have different results (Alizadeh et al., 2001; Rakha et al., 2007). The clinical course of a patient with breast carcinoma remains difficult to predict, as tumors of apparently homogenous morphological characteristics still vary in response to therapy and have divergent outcomes. Chemo prevention is another method to treat cancer. Using natural or manmade products to treat cancers is called cancer. It is considered along, proficient and reversible process to treat invasive and multistage cancers (Kuo et al., 2005). Chemoprevention has been studied a lot in recent years. Cowania mexicana (rosaceae) is found in North America. Its leaves and branches showed antitumor activity by strongly inhibiting the PCGF2 protein (also known as ring finger protein 110) involved in formation of breast adenocarcinoma. This plant has other medicinal properties. It has been used against respiratory disease and cough. Mixed extract of herbs or plants might contain different chemo preventive chemotherapeutic compounds with more than one mechanism of action (Hu et al., 2002). Recent studies show that rosaceous plants have an abundant amount of polyphenols that have various biological activities. I have examined the polyphenols and their derivatives of this plant. In this paper I have characterized polyphenols extracted from Cowania mexicana and its derivates and checked their antitumor activity by examining their inhibitory effect on PCGF2.

Phenotypic behavior of cancer cells is not only controlled by cell autonomous signals, but it is also affected by adjoining stormal cells (Barbarestani et al., 2006). Ring finger is a pattern of conserved histidines and cysteines that synchronize two zinc atoms in a cross-brace system, a ligation scheme distinct from those of classical zing finger 1 
and 2 (Yin et al., 1999). Ring finger protein causes formation of multiprotein complexes and mediates interactions between different proteins (Hamamoto et al., 2004). RING finger plays major role in the binding to promoter specificity protein 1 (sp1) (Brindha et al., 2009) even though breast cancer death rates have been lowered to $34 \%$ since 1990 , not all parts of the population had an advantage from this decrease (DeSantisetal.,2014). Treatment of cancer is along and tiring procedure. It is an expensive, inconvenient and not easily available everywhere, but the main problem is harmful side effects caused by cancer drugs (Hilakivi-Clarke et al., 1994). For example, it is considered that if chemotherapy is carried out for longer periods, it makes the immunological defense system of the patient's body weak which may result in him being in danger of more diseases and infections by making his body susceptible to them. RING- finger motif in BRCA 1 is part of a larger N-terminal structural domain. Families that have a genetic history of ovarian and breast cancer have many mutations at this site (Ameyar et al., 1998).

\section{Materials and Methods}

In the field of biotechnology and pharmacy drug designing is the method by which drugs are found and made. It is a process by which drugs are formed on the basis of design and on the basis of what the drug targets are, using bioinformatics. Drug developing is not an easy process. It requires time, patience, and expertise (Yaminiand Vijjulatha, 2008). Drug designing starts with the finding of a right target compound responsible for causing disease (Zyad et al., 2008). Drug designing and drug formation is very important for human health. Its success depends upon the expertise and new techniques by using both biological and chemical research. For this process computational method is adopted. It is usually joined with structural information obtained from and nuclear magnetic resonance investigation and macromolecular crystallography. Recent studies have helped us to develop large libraries of possible bioactive compounds by combinational methods, which will play an important role in drug discovery (Agrafiootis et al., 2008).

\section{Software Required}

1. Pymol

2. Autodock

3. Discoverystudio4.1

4. Autodock vina

5. Medchem.

\section{Disease Selection}

A human body undergoes many complex biochemical procedures which make and recycle different compounds in a well coordinated and in a balanced way. A disease is basically produced when the rear changes in these biochemical pathways (Yu et al., 2007). When developing a drug we first need to understand the basic biological nature and symptoms caused by a disease to understand whether it is caused by an antigen which may be any infectious agent like bacteria or virus, a synthetic compound or a protein (Tisdale,2004). When we are selecting a disease for development of a drug, there are many factors involved like pathogenesis of a disease, evolution of a disease, involved proteins, its death rate, how many drugs are already available, their side effects and their efficiency, etc.

\section{Target Molecule Prediction}

Target molecule means the target protein which is a causative agent of the disease we want to form the drug against (McInnes, 2007). The cellular targets of many drugs are generally proteins. The drugs act by binding to receptor molecules (Briscoe, 2009). It will either increase or stop its activity (Dobson and Barnett, 2008). In case of a disease, when drug is given to the effected person it will bind with the target molecule, taking part in the formation of a disease. The drug will try to inhibit the contribution of the target molecule to stop the disease from progress. Drugs function in two ways they either start or stop the activity of target molecule (Stockwell, 2007). The target should be the main key molecule which initiates the disease by signaling or metabolic pathway. The target molecule can be a protein or DNA; it depends on the disease mechanism.

\section{Molecular Docking}

I downloaded pdb file of protein from protein data bank and downloaded the ligands files as sdf from the pub chem. database. Then modified the structure of ligands in discovery studio 4.1 and opened the protein in discovery studio 4.1 and remove the water molecules in discovery studio 4.1 and saved as pdb files. Then I opened protein in autodock and made a grid box and values were

center_x $=38.78$

center_ $\mathrm{y}=17.896$

center_z=99.74

size_ $\mathrm{x}=76$

size $\_=80$

size $z=126$

And saved as pdbqt files then opened the ligand in autodock and saved as pdbqt files. Protein and ligands opened in autodock vina and precede docking and got the results.

\section{Results and Discussions}

The code of target protein is 2 hod. The PDB file of target protein was downloaded from NCIB. I found five ligands and modified their structures one by one. After that I started docking. The ligands chosen were apigenin, hesperidin, menisdaurin, pedunculagin, procyanidinB5. I modified them as shown in Table 1 
Table 1. Modifications done to the Original Ligands.

\begin{tabular}{llll}
\hline Ligand name & $\mathbf{R 1}$ & $\mathbf{R 2}$ & R3 \\
\hline Apigenin & $\mathrm{H}_{21} \rightarrow \mathrm{N}_{21}$ & $\mathrm{H}_{27 \rightarrow} \mathrm{O}_{27}$ & $\mathrm{H}_{22 \rightarrow} \mathrm{P}_{22}$ \\
Hesperidin & $\mathrm{H}_{74 \rightarrow} \mathrm{O}_{74}$ & $\mathrm{O}_{13 \rightarrow} \rightarrow \mathrm{C}_{13}$ & $\mathrm{H}_{62} \rightarrow \mathrm{O}_{62}$ \\
Menisdaurin & $\mathrm{H}_{41 \rightarrow} \mathrm{O}_{41}$ & $\mathrm{H}_{39 \rightarrow} \rightarrow \mathrm{O}_{39}$ & $\mathrm{O}_{2 \rightarrow} \mathrm{N}_{2}$ \\
Pedunculagin & $\mathrm{O}_{9 \rightarrow} \mathrm{N}_{9}$ & $\mathrm{H}_{57 \rightarrow} \rightarrow \mathrm{O}_{57}$ & $\mathrm{H}_{71} \rightarrow \mathrm{N}_{71}$ \\
ProcyanidinB5 & $\mathrm{H}_{68 \rightarrow} \mathrm{N}_{68}$ & $\mathrm{H}_{53} \rightarrow \mathrm{O}_{53}$ & $\mathrm{H}_{61} \rightarrow \mathrm{P}_{61}$ \\
\hline
\end{tabular}<smiles>NNc1c(-c2ccc(O)c(O)c2)oc2c(P)c(O)cc(O)c2c1=O</smiles>

Apigenin.

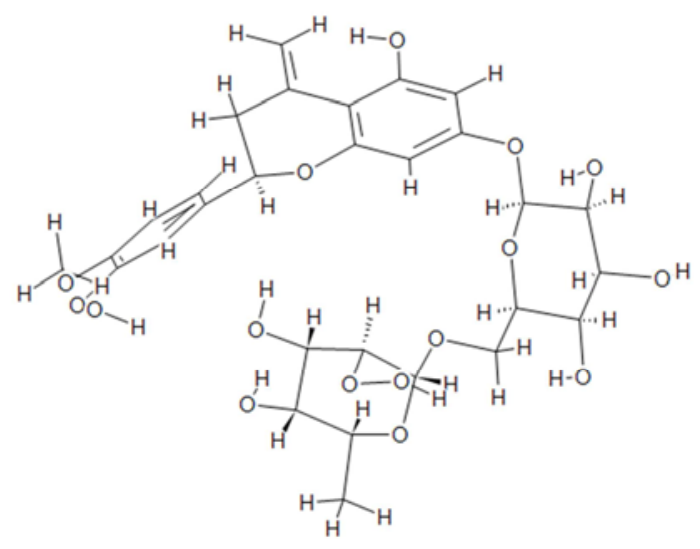

Menisdaurin.

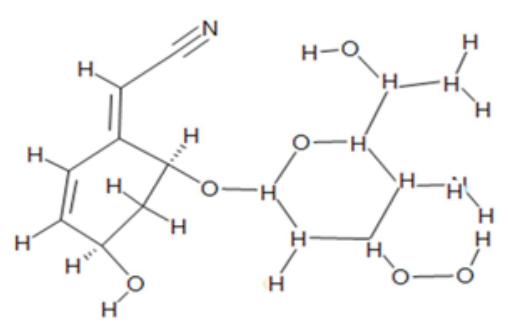

Hesperidin.

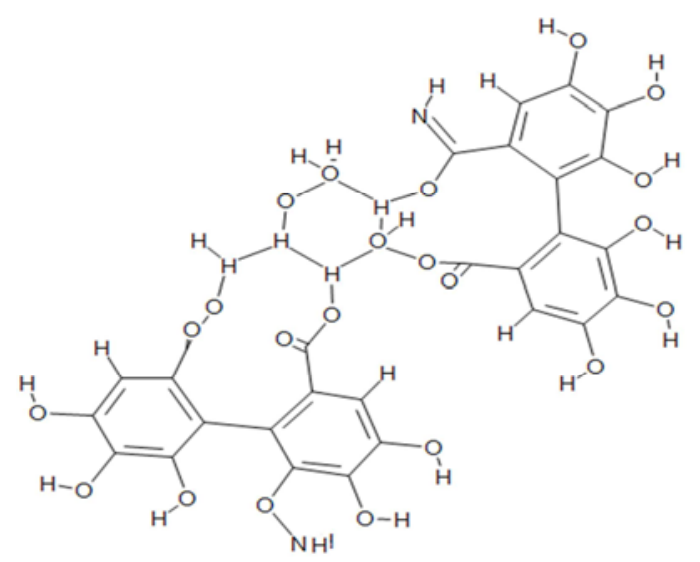

Pedunculagin.

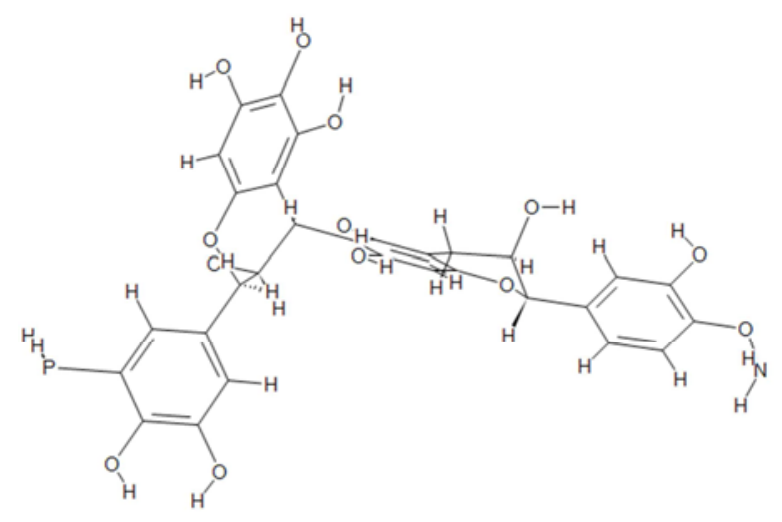

ProcyanidinB5.

Ligands interaction with the target protein:

1. Apigenin derivative:
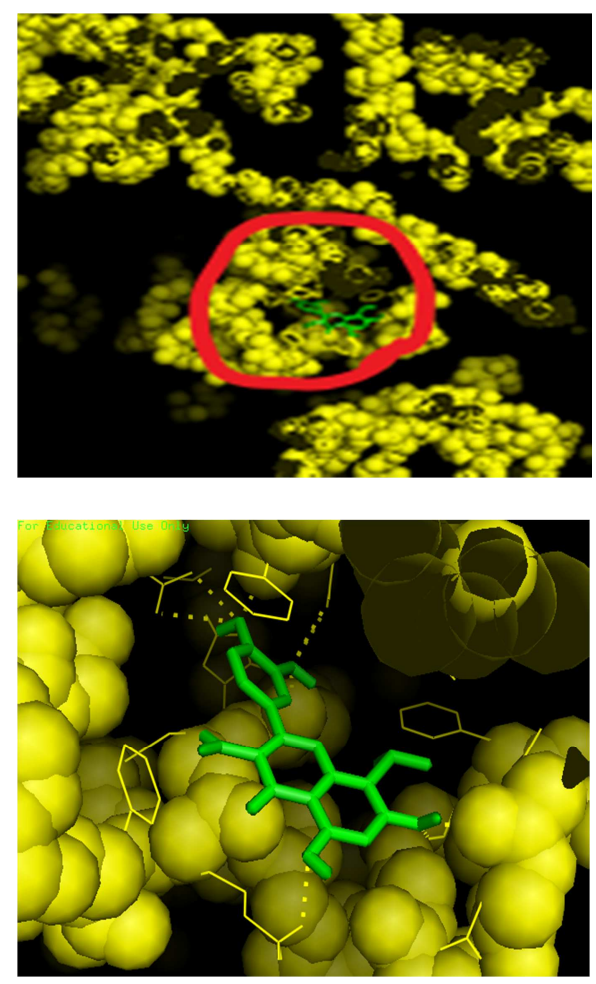

Figure 1. Predicted Bonded Interaction between Modified Apigenin with PCGF2 Protein.

2. Hesperidin derivative:

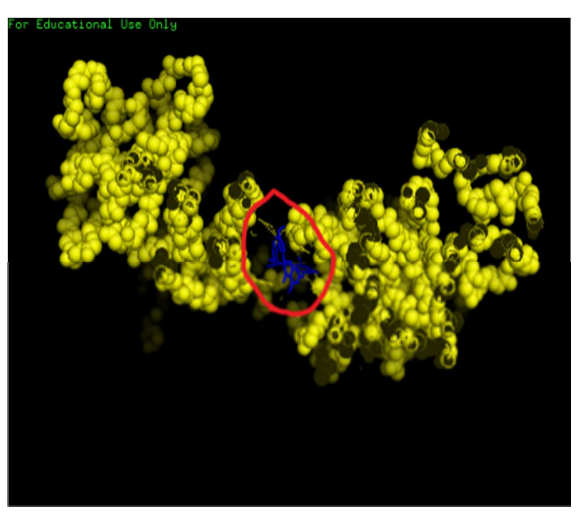




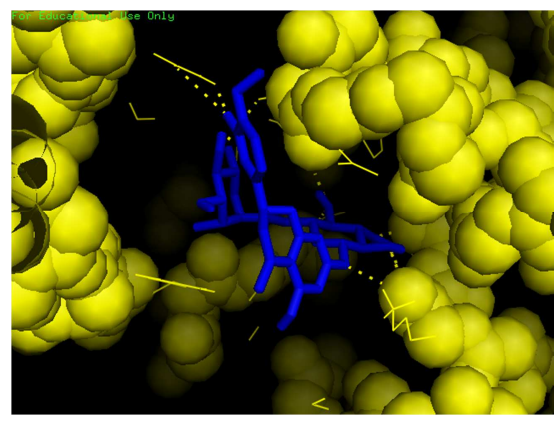

Figure 2. Predicted Bonded Interaction between Hesperidin Derivative with PCGF2 Protein

3. Menisdaurin derivative:
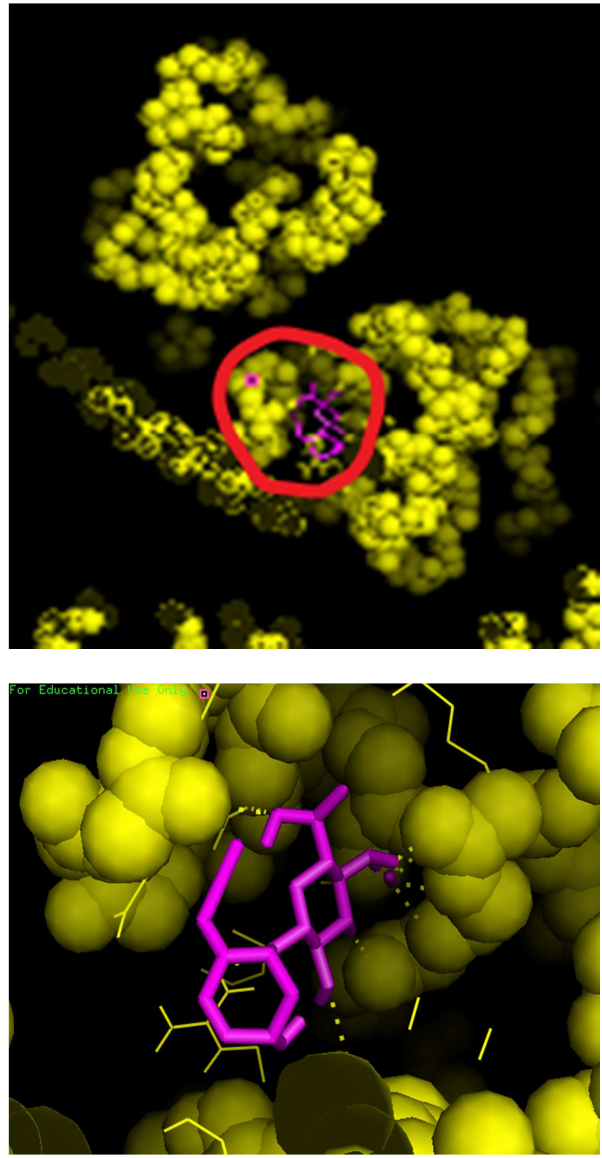

Figure 3. Predicted Bonded Interaction between Menisdaurin Derivative with PCGF2 Protein.

4. Pedunculagin derivative:

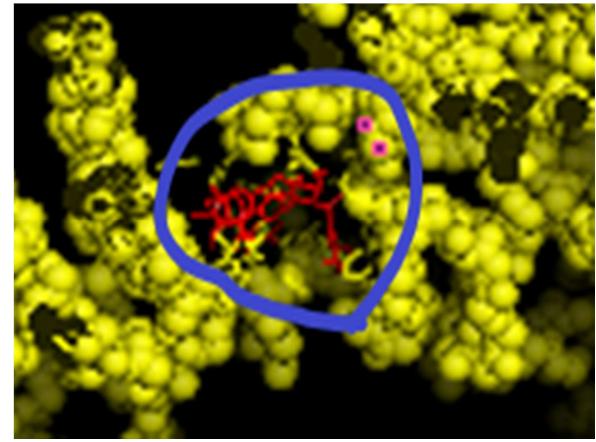

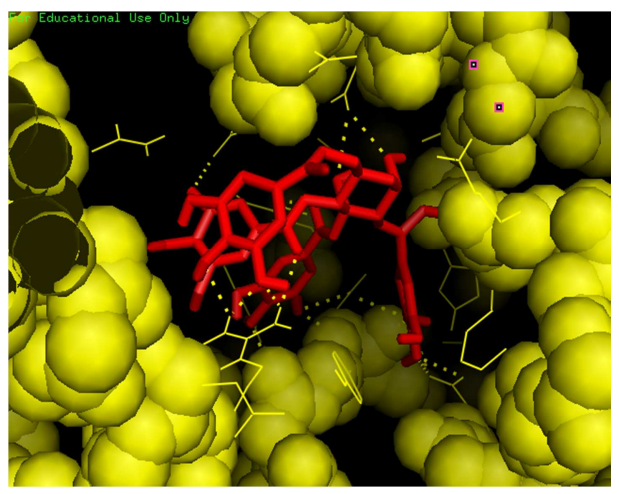

Figure 4. Predicted Bonded Interaction between Pedunculagin Derivative with PCGF2 Protein.

5. Procyanidin B5 derivative:
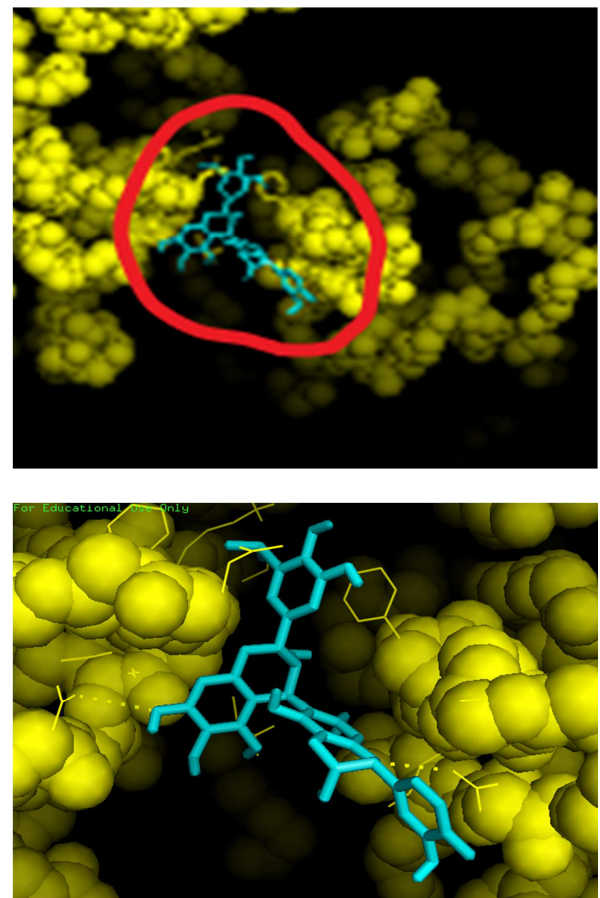

Figure 5. Predicted Bonded Interaction between Procyanidin B5 Derivative with PCGF2 Protein.

DOCKINGRESULTSOFLIGANDSWITHPROTIEN:

Table 2. Docking Energies of Different Ligands with PCGF2 Protein.

\begin{tabular}{llllllllll}
\hline Name & Ligands & $\mathbf{1}$ & $\mathbf{2}$ & $\mathbf{3}$ & $\mathbf{4}$ & $\mathbf{5}$ & $\mathbf{6}$ & $\mathbf{7}$ & $\mathbf{8}$ \\
\hline \multirow{2}{*}{ Apigenin } & Orgnl & -8.3 & -8.1 & -8.1 & -8.0 & -8.0 & -8.0 & -7.9 & -7.8 \\
& Modif & -8.7 & -8.3 & -8.0 & -7.8 & -7.8 & -7.6 & -7.6 & -7.6 \\
\multirow{3}{*}{ Hesperidin } & Orgnl & -8.5 & -8.2 & -8.2 & -8.1 & -8.0 & -8.0 & -7.7 & -7.7 \\
& Modf & -9.5 & -9.3 & -9.1 & -8.9 & -8.9 & -8.7 & -7.9 & -7.8 \\
& Orgnl & -7.4 & -7.4 & -7.3 & -7.1 & -6.9 & -6.9 & -6.9 & -6.9 \\
\multirow{4}{*}{ Pedunculaginin } & Orgnl & -10.5 & -7.7 & -7.7 & -7.3 & -7.3 & -7.3 & -7.3 & -7.2 \\
& Modf & -10.5 & -10.4 & -10.3 & -10.2 & -10.2 & -9.9 & -9.4 \\
\multirow{4}{*}{ ProcyanidinB5 } & Orgnl & -10.1 & -10.0 & -9.9 & -9.8 & -9.7 & -9.7 & -9.7 & -9.6 \\
& Modf & -9.3 & -9.2 & -9.1 & -9.0 & -8.9 & -8.8 & -8.6 & -8.6 \\
& 9.0 & -8.9 & -8.5 & -8.5 & -8.5 & -8.1 & -8.1 & -8.1 \\
\hline
\end{tabular}

ABMETproperties:

ADMET properties of modified ligands extracted from Cowania mexicana are given below in Table 3 
Table 3. ADMET Properties of Modified Ligands.

\begin{tabular}{|c|c|c|c|c|c|c|c|c|c|}
\hline Structure name & MlogP & $S+\log P$ & $S+\log D$ & Rule of 5 & Ruleof5_code & MWT & M_NO & T_PSA & HBDH \\
\hline Ligand 1 (mdf apigenin) & -0.235 & 3.018 & 3.018 & 1.000 & $\mathrm{Hb}$ & 333.239 & 7.000 & 137.150 & 6.000 \\
\hline Ligand 2 (mdf hesperidin) & -1.563 & -0.212 & -0.235 & 3.000 & $\mathrm{Hb}, \mathrm{Mw}, \mathrm{NO}$ & 640.599 & 16.000 & 235.680 & 8.000 \\
\hline Ligand 3 (mdf menisdaurin) & -1.595 & -1.238 & -1.806 & 1.000 & $\mathrm{Hb}$ & 342.351 & 9.000 & 158.420 & 6.000 \\
\hline Ligand 4 (mdf pedunculagin) & -5.377 & -0.075 & -0.796 & 3.000 & $\mathrm{Hb}, \mathrm{Mw}, \mathrm{NO}$ & 814.585 & 24.000 & 419.450 & 16.000 \\
\hline Ligand 4 (mdf procyanidin) & -1.458 & 2.545 & 2.599 & 3.000 & $\mathrm{Hb}, \mathrm{Mw}, \mathrm{NO}$ & 641.529 & 14.000 & 256.010 & 12.000 \\
\hline
\end{tabular}

Table 4. Drug Scoring of Modified Ligands.

\begin{tabular}{lllll}
\hline LIGANDNAME & ligand & Rmsd & Rank(score) & score \\
\hline Ligand1 & 0 & None & 1 & 577 \\
Ligand2 & 0 & None & 1 & 668 \\
Ligand3 & 0 & none & 1 & 44 \\
Ligand4 & 0 & none & 1 & 344 \\
Ligand5 & 0 & none & 1 & -97 \\
\hline
\end{tabular}

\section{Conclusion}

Our molecular docking results show that the derivatives of the compounds we selected for this study i.e. Pedunculagin, Procyanidin 5, Hesperidin, Menisdaurin and Apigenin showed better interaction with the target protein PCGF2. These results show that these compounds can prove novel in our fight against breast cancer.

\section{References}

[1] Alizadeh AA, Ross DT, Perou CM and Van De Rijn M (2001) towards a novel classification of human malignancies based on gene expression patterns. The Journal of pathology 195: 41-52.

[2] Ameyar M, Atfi A, Cai Z, Stancou R, Shatrov V, Bettaïeb Aand Chouaïb S (1998) Analysis of Human Breast Adenocarcinoma MCF7 Resistance to Tumor Necrosis Factorinduced

[3] Cell Death LACK OF CORRELATION BETWEEN JNK ACTIVATION AND CERAMIDE PATHWAY. Journal of Biological Chemistry 273: 29002-29008.

[4] Barbarestani M, Ragerdi KashaniI, Etesam F, Shokrgozar MA, Abdolvahabi MA, Haddad P, Mokohi N, Hossein Mand Hosseni M (2006) Evaluation of human breast adenocarcinoma (MCF-7) cells proliferation inco culture with human adipocytesin three dimensional collagen gel matrix: norepine phrineas alipolytic factor. Iranian Biomedical Journal 10: 125-131.

[5] Brindha V, Saravanan A and Manimekalai R (2009) Drug designing for ringfinger protein 110 involved in adenocarcinoma (human breast cancer) using casuarinin extracted from Terminalia arjuna. Indian Journal of Science and Technology 2: 22-26.

[6] Briscoe CJ (2009) Advances in the application of high performance affinity chromatography to bioanalysis and approaches for improving the quality and reliability of bioanalytical data, The University of Nebraska-Lincoln.

[7] De Santis C, Ma J, Bryan Land Jemal A (2014) Breast cancer statistics, 2013. CA: a cancer journal for clinicians 64: 52-62.

[8] De Santis C, Siegel R, Bandi Pand Jemal A (2011) Breast cancer statistics, 2011. CA: a cancer journal for clinicians 61: 408-418.

[9] Dobson A J and Barnett A (2008) An introduction to generalized linear models, CRC press.

[10] Hamamoto R, Furukawa Y, Morita M, Iimura Y, Silva FP, LiM, Yagyu Rand Nakamura Y (2004) SMYD3 encodes a histone methyl transferase involved in the proliferation of cancer cells. Nature cell biology 6.

[11] Hilakivi-Clarke L, Rowland J, Clarke R and Lippman ME (1994) Psychosocial factors in the development and progression of breast cancer. Breast Cancer Research and Treatment 29: 141-160.

[12] HuH, Ahn NS, YangX, Lee Y S and Kang K S (2002) Gano dermalucid umex tract induces cell cycle arrest and apoptosis in MCF-7 human breast cancer cell. International Journal of Cancer 102: 250-253.

[13] Kuo P-L, Hsu Y-L, Lin T-C, Chang J-Kand Lin C-C (2005) Induction of cell cycle arrest and apoptosis in human nonsmall cel lung cancer A549 cells by casuarinin from the bark of Terminalia arjuna Linn. Anti-cancer drugs 16: 409-415.

[14] Mc Innes C (2007) Virtual screening strategies in drug discovery. Current opinion in chemical biology 11: 494-502.

[15] Rakha E A, El-Sayed ME, Green AR, Lee AH, Robertson JF and Ellis IO (2007) Prognostic markers in triple-negative breast cancer. Cancer 109: 25-32.

[16] Stockwell RG (2007) A basis for efficient representation of the S-transform. Digital Signal Processing 17: 371-393.

[17] Tisdale MJ (2004) Tumor-host interactions. Journal of cellular biochemistry 93: 871-877.

[18] Yamini Land Vijjulatha M (2008) Inhibitors of human dihydrofolate reductase: a computational design and docking studies Using glide. Journal of Chemistry 5: 263-270.

[19] YinX-Y, Gupta K, Han WP, Levitan ES and Prochownik EV (1999) Mmip-2, a novel RING finger protein that interacts with mad members of the Myconco protein network. Oncogene 18.

[20] Yu J, Vodyanik MA, Smuga-Otto K, Antosiewicz-Bourget J, Frane JL, Tian S, Nie J, Jonsdottir GA, Ruotti V and Stewart $\mathrm{R}$ (2007) Induced pluripotent stem cell in es derived from human somatic cells. Science 318: 1917-1920. 